Article

\title{
Titanate Nanotube-Supported Au-Rh Bimetallic Catalysts: Characterization and Their Catalytic Performances in Hydroformylation of Vinyl Acetate
}

\author{
Ya Chen ${ }^{1}$, Penghe Su ${ }^{1}$, Xiaotong Liu ${ }^{1}$, Hongchi Liu ${ }^{1}$, Baolin Zhu ${ }^{1}$, Shoumin Zhang ${ }^{1}$ \\ and Weiping Huang 1,2,3,* \\ 1 College of Chemistry, Nankai University, Tianjin 300071, China; xiaoyayaking@163.com (Y.C.); \\ sph_edu@163.com (P.S.); jenalia@163.com (X.L.); h335liu@edu.uwaterloo.ca (H.L.); \\ zhubaolin@nankai.edu.cn (B.Z.); zhangsm@nankai.edu.cn (S.Z.) \\ 2 Collaborative Innovation Center of Chemical Science and Engineering (Tianjin), Tianjin 300071, China \\ 3 The Key Laboratory of Advanced Energy Materials Chemistry (Ministry of Education), Nankai University, \\ Tianjin 300071, China \\ * Correspondence: hwp914@nankai.edu.cn; Tel.: +86-138-2009-6974
}

Received: 5 September 2018; Accepted: 21 September 2018; Published: 26 September 2018

\begin{abstract}
A series of titanate nanotube-supported metal catalysts ( $\mathrm{M} / \mathrm{TNTs}, \mathrm{M}=\mathrm{Rh}, \mathrm{Au}$ orAu-Rh) were facilely synthesized. The effects of different Au contents, reduction processes and sequence of loading metals on their catalytic performances in the hydroformylation of vinyl acetate were comparatively investigated. The results showed that some Au and Rh formed bimetallic particles. Furthermore, the presence of $\mathrm{Au}$ in catalysts could significantly improve the selectivity of reaction for aldehydes. Compared with the monometallic catalysts ( $\mathrm{Rh}_{0.33} / \mathrm{TNTs}-1$ and $\left.\mathrm{Au}_{0.49} / \mathrm{TNTs}-2\right)$, the resultant bimetallic catalysts exhibited significantly higher selectivity for aldehydes as well as higher TOF values in the hydroformylation of vinyl acetate. Among them, $\mathrm{Au}_{0.52} / \mathrm{Rh}_{0.32} / \mathrm{TNTs}-12$ displayed the best catalytic performance. The corresponding selectivity for aldehydes was as high as $88.67 \%$ and the turnover frequency (TOF) reached up to $3500 \mathrm{~h}^{-1}$. In addition, for the reduction of $\mathrm{Rh}^{3+}$ and $\mathrm{Au}^{3+}$ ions, the photo-reduction and ethanol-reduction were the optimal techniques under the present conditions, respectively.
\end{abstract}

Keywords: titanate nanotubes; rhodium; gold; hydroformylation; vinyl acetate

\section{Introduction}

Hydroformylation is a process of producing fatty aldehydes with one more carbon atom compared to the original olefins with carbon monoxide and hydrogen in the presence of catalysts under pressure [1-4]. Since its discovery in 1938, the hydroformylation reaction has become an important one-step synthesis pathway for aldehydes from a wide range of cheap olefins. In the industrial field, more than 12 million tons of aldehydes worldwide are produced by the hydroformylation reaction every year. Unti now, the homogeneous catalysts that are widely used in hydroformylation in the industrial field are usually mononuclear complexes, which display remarkable catalytic performance [5-8]. However, it is difficult to separate these homogeneous catalysts from the reaction system. To overcome the difficulty, many strategies have been developed, such as aiming to heterogenize the homogeneous catalysts by anchoring them to various solid supports [9-13].

Compared with $\mathrm{Ir}, \mathrm{Co}, \mathrm{Pd}$ and $\mathrm{Ru}$, Rh-based catalysts are able to catalyze the hydroformylation reaction with a higher efficiency at a relatively lower reaction temperature and pressure [14-17]. Numerous inorganic and organic polymer materials, such as zeolite [18], activated carbon [19], porous organic polymers [20], nonmetal oxides [21] and metal-organic frameworks [22] have been 
developed as supports for rhodium for hydroformylation. Among these supports, titanate nanotubes (TNTs) with a large surface area and multi-wall structure have been reported as an excellent choice $[23,24]$.

For the hydroformylation of functionalized olefins (e.g., vinyl acetate), the functional group in the molecule may coordinate with the catalytic center $[25,26]$. It is this coordination that may reduce the catalytic activity of the catalyst and make it difficult to control and regulate its selectivity towards the target product in the hydroformylation of functionalized olefins [27]. It is well known that the catalytic activity and selectivity of poly metallic catalyst are usually quite different from those of monometallic catalyst due to the synergistic effects [28-31]. However, there are also positive changes as the polymetallic catalyst consists of intermediates, which have both multi-metallic and monometallic compounds [32-35]. Klahn et al. reported that the synergism of rhodium and rhenium in the complexes could dramatically enhance the catalytic performance in catalytic hydroformylation [36]. The mononuclear intermediate $\left(\mathrm{H}_{\mathrm{x}} \mathrm{RCORh}(\mathrm{CO})_{\mathrm{y}}\right)$ and binuclear intermediate $\left(\mathrm{H}_{\mathrm{n}} \operatorname{Rh} \mathrm{Re}(\mathrm{CO})_{\mathrm{m}}\right)$ were found to exist simultaneously in the catalytic cycle. On the other hand, studies have revealed that gold nanoparticles displayed excellent activity and selectivity in some catalytic reactions [37-39]. Ma et al. [40] reported that the presence of gold could promote the in situ-reduction of $\mathrm{Co}_{3} \mathrm{O}_{4}$ to metallic cobalt under reaction conditions, thereby increasing the number of active sites for the tandem hydroformylation and hydrogenation of dicyclopentadiene.

In our previous work [41], we found that the Rh-Ru/TNTs bimetallic catalysts with two types of active sites showed satisfactory catalytic performance in cyclohexene hydroformylation but poor selectivity for aldehydes in hydroformylation of vinyl acetate. The Rh/TNTs catalysts also exhibited a relatively lower selectivity for aldehydes [42]. In the present contribution, we designed the $\mathrm{Au}-\mathrm{Rh} / \mathrm{TNTs}$ catalysts for hydroformylation of vinyl acetate, in which gold is expected to provide more free coordination sites for substrates and work synergistically with rhodium to enhance the yield of aldehydes. In addition, the effects of different Au contents and reduction processes on their catalytic performance were investigated in detail.

\section{Results and Discussion}

\subsection{Characterization of Catalysts}

The metal contents are measured by ICP analysis. The contents of metals and SSA of the prepared samples are listed in Table 1. As shown in Table 1, SSA of $\mathrm{Au}_{\mathrm{x}} / \mathrm{Rh}_{\mathrm{y}} / \mathrm{TNTs}-12$ (Entry 3-6) are lower than that of pure TNTs (SSA $=284.6 \mathrm{~m}^{2} / \mathrm{g}$ ) and decrease gradually with an increase in Au loadings. This can be ascribed to the fact that the bimetallic species deposited on the outer or inner surfaces of TNTs block the adsorption sites of TNTs for nitrogen molecules. At the same time, the catalysts (Entry 4, 7, 8 and 9) with similar metal loadings show differences in SSA. This could be caused by the different reduction methods and sequence of loading metals, which results in different sizes of metal particles. The EDX spectra and elemental mapping of Ti, $\mathrm{O}$, Rh and $\mathrm{Au}$ in $\mathrm{Au}_{0.52} / \mathrm{Rh}_{0.32} / \mathrm{TNTs}-12$ are shown in Figure 1. It can be seen that $\mathrm{Rh}$ and $\mathrm{Au}$ species are highly dispersed on the support.

Table 1. Contents of Rh and Au in catalysts and the specific surface area of the prepared catalysts.

\begin{tabular}{cccccc}
\hline Entry & Catalysts & $\begin{array}{c}\text { Contents of } \mathbf{R h}, \\
\mathbf{A u} / \mathbf{w t} \%\end{array}$ & $\mathbf{S S A} / \mathbf{m}^{2} / \mathbf{g}$ & $\begin{array}{c}\text { Max. Particle } \\
\text { Size/nm } \\
\mathbf{( A u - R h )}\end{array}$ & $\begin{array}{c}\text { Average Particle } \\
\text { Size/nm } \\
\text { (Au-Rh) }\end{array}$ \\
\hline 1 & $\mathrm{Rh}_{0.33} / \mathrm{TNTs}-1$ & $0.33,0$ & 233.5 & 2 & 2 \\
2 & $\mathrm{Au}_{0.49} / \mathrm{TNTs}-2$ & $0,0.49$ & 268.6 & 3 & 2 \\
3 & $\mathrm{Au}_{0.28} / \mathrm{Rh}_{0.34} / \mathrm{TNTs}-12$ & $0.34,0.28$ & 254.3 & 3 & 2 \\
4 & $\mathrm{Au}_{0.52} / \mathrm{Rh}_{0.32} / \mathrm{TNTs}-12$ & $0.32,0.52$ & 226.2 & 6 & 5 \\
\hline
\end{tabular}


Table 1. Cont.

\begin{tabular}{clcccc}
\hline Entry & Catalysts & $\begin{array}{c}\text { Contents of } \mathbf{R h}, \\
\mathbf{A u} / \mathbf{w t} \%\end{array}$ & $\mathbf{S S A} / \mathbf{m}^{\mathbf{2} / \mathbf{g}}$ & $\begin{array}{c}\text { Max. Particle } \\
\text { Size/nm } \\
\mathbf{( A u - R h )}\end{array}$ & $\begin{array}{c}\text { Average Particle } \\
\text { Size/nm } \\
(\mathbf{A u - R h )}\end{array}$ \\
\hline 5 & $\mathrm{Au}_{0.78} / \mathrm{Rh}_{0.31} / \mathrm{TNTs}-12$ & $0.31,0.78$ & 208.3 & 14 & 8 \\
6 & $\mathrm{Au}_{0.98} / \mathrm{Rh}_{0.33} / \mathrm{TNTs}-12$ & $0.33,0.98$ & 164.5 & 16 & 12 \\
7 & $\mathrm{Au}_{0.49} / \mathrm{Rh}_{0.33} / \mathrm{TNTs}-22$ & $0.33,0.49$ & 218.8 & 10 & 5 \\
8 & $\mathrm{Au}_{0.50} / \mathrm{Rh}_{0.32} / \mathrm{TNTs}-11$ & $0.32,0.50$ & 207.6 & 18 & 5 \\
9 & $\mathrm{Rh}_{0.31} / \mathrm{Au}_{0.51} / \mathrm{TNTs}-21$ & $0.31,0.51$ & 220.1 & 10 & 5 \\
10 & $\mathrm{Au}_{0.52} / \mathrm{Rh}_{0.32} / \mathrm{TNTs}-12^{*}$ & $0.32,0.52$ & 212.3 & 26 & 13 \\
\hline
\end{tabular}

$\mathrm{Au}_{0.52} / \mathrm{Rh}_{0.32} / \mathrm{TNTs}-12^{*}$ : obtained by calcination of $\mathrm{Au}_{0.52} / \mathrm{Rh}_{0.32} / \mathrm{TNTs}-12$ at $300{ }^{\circ} \mathrm{C}$ for $2 \mathrm{~h}$ in argon atmosphere; Max. particle size: the diameter of the largest metal particle in the TEM images of catalysts; Average particle size is calculated by the following formula: Average particle size $=\operatorname{sigma}(\mathrm{Nd} 3) / \operatorname{sigma}(\mathrm{Nd2})$, where $\mathrm{d}$ is the particle size and $\mathrm{N}$ is the number of particles with this size.
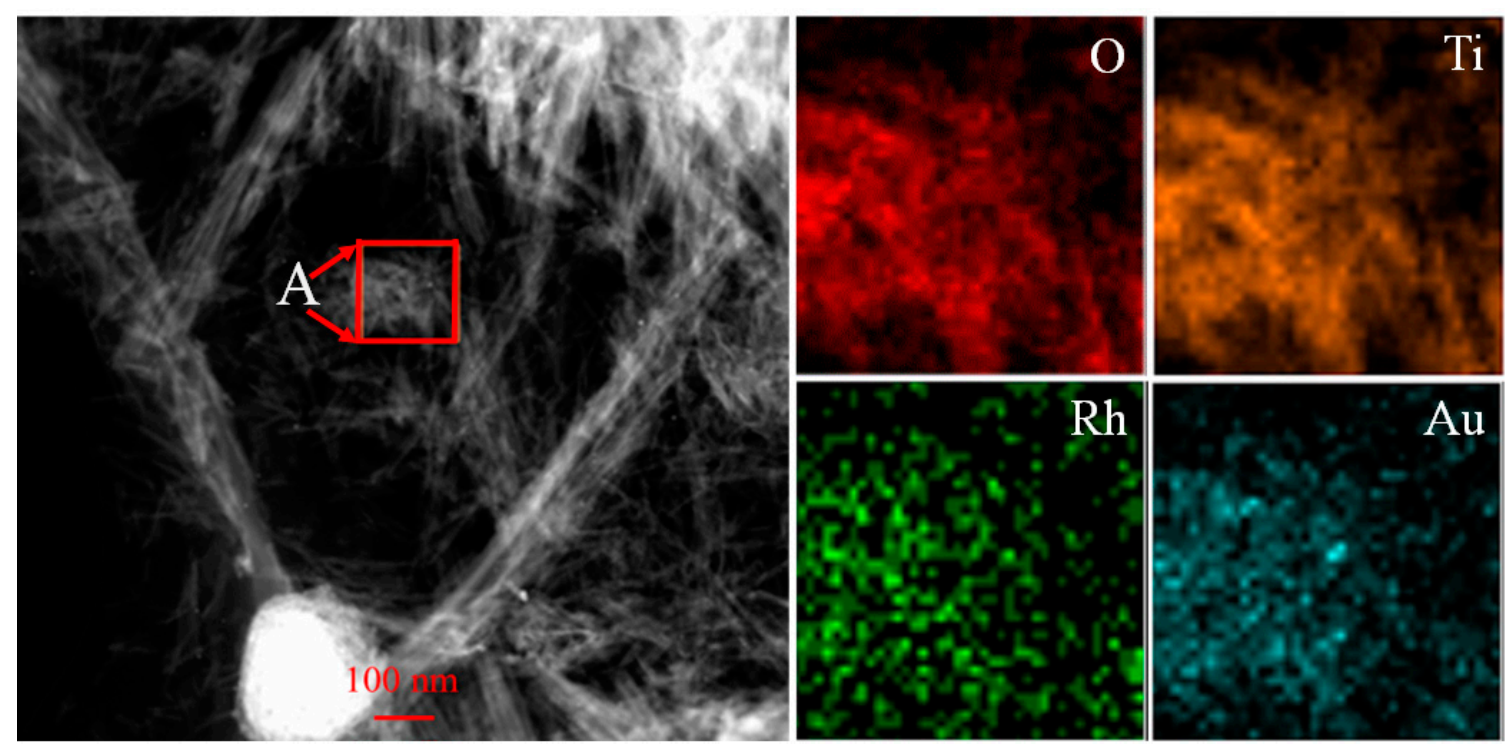

Figure 1. HAADF-STEM image of $\mathrm{Au}_{0.52} / \mathrm{Rh}_{0.32} / \mathrm{TNTs}-12$ (A) and EDX mapping of $\mathrm{O}, \mathrm{Rh} \mathrm{Ti}$ andAu in the marked area of A.

The XRD patterns, which are shown in Figure 2, reveal that all the catalysts display obvious diffraction peaks at $2 \theta=25.28^{\circ}, 37.8^{\circ}$ and $48.05^{\circ}$, which are attributed to the (101), (004) and (200) reflections of the anatase $\mathrm{TiO}_{2}$ (JCPDS21-1272), respectively. This indicates that after the incorporation of the metals, the support still maintains its crystal structure. Furthermore, no characteristic peak related to $\mathrm{Au}$ and $\mathrm{Rh}$ appears in their patterns. This may be explained by the pretty low concentration and high dispersion of the metals, which is in accordance with the EDX analysis. 


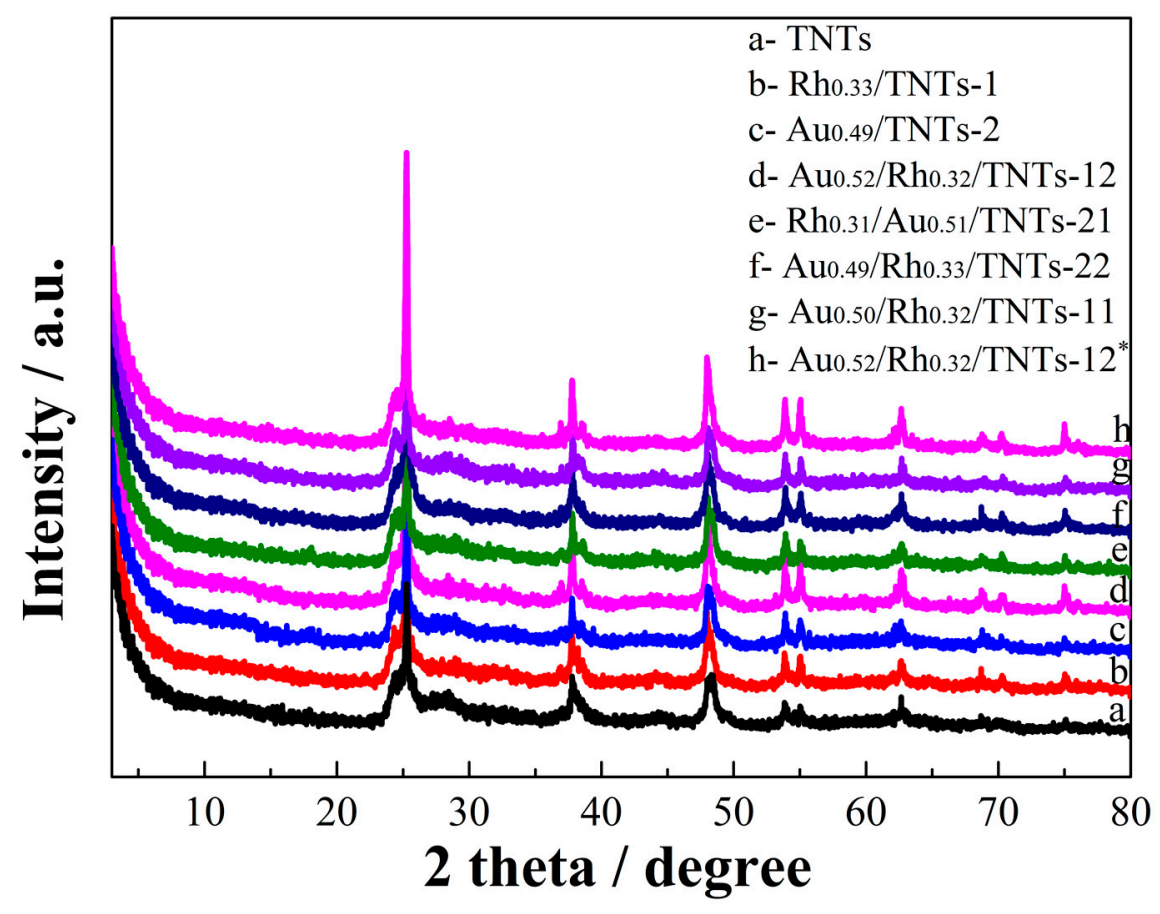

Figure 2. XRD patterns of the prepared catalysts.

The TEM images of the resultant catalysts are shown in Figure 3 and the particle size distribution (PSD) of metals in the as-prepared catalysts are exhibited in Figure S1. The average particle size distribution of metals in the as-prepared samples was statistically calculated, which is shown in Table 1 and Figure S2. The interlayer spacing and inner diameter of the TNTs are about $0.7-0.9 \mathrm{~nm}$ and 4-6 nm, respectively (Figure S1A). Uniform black spots can be observed on both $\mathrm{Rh}_{0.33} / \mathrm{TNTs}-1$ (Figure $3 \mathrm{~A}$ ) and $\mathrm{Au}_{0.49} / \mathrm{TNTs}-2$ (Figure S1B). The average diameter of the black spots is about 2-3 $\mathrm{nm}$, demonstrating that $\mathrm{Rh}$ and $\mathrm{Au}$ nanoparticles in the two catalysts do not visibly aggregate. Furthermore, it can be seen from Figure 3A and Figure S1B that TNTs still maintain their perfect tubular morphology and clear multi-wall structure after the loading process. The TEM images of $\mathrm{Au}_{\mathrm{x}} / \mathrm{Rh}_{\mathrm{y}} / \mathrm{TNTs}-12$ show that the size of metal particles increases gradually with an increase in $\mathrm{Au}$ content (Table 1). The changes in particle size demonstrate that the agglomeration degree of bimetallic species increases with the augmentation of $A u$ content in $\mathrm{Au}_{\mathrm{x}} / \mathrm{Rh}_{\mathrm{y}} / \mathrm{TNTs}-12$. In the inset of Figure 3B, the lattice spacing of $2.4 \AA$ might be the (1 11 ) plane of Rh, while the lattice spacing of $2.2 \AA$ could be assigned to (1 111 ) plane of $\mathrm{Au}$. This gives direct evidence that some of the two metals form complex metal particles, which essentially represents the strong interactions between the two metals. 

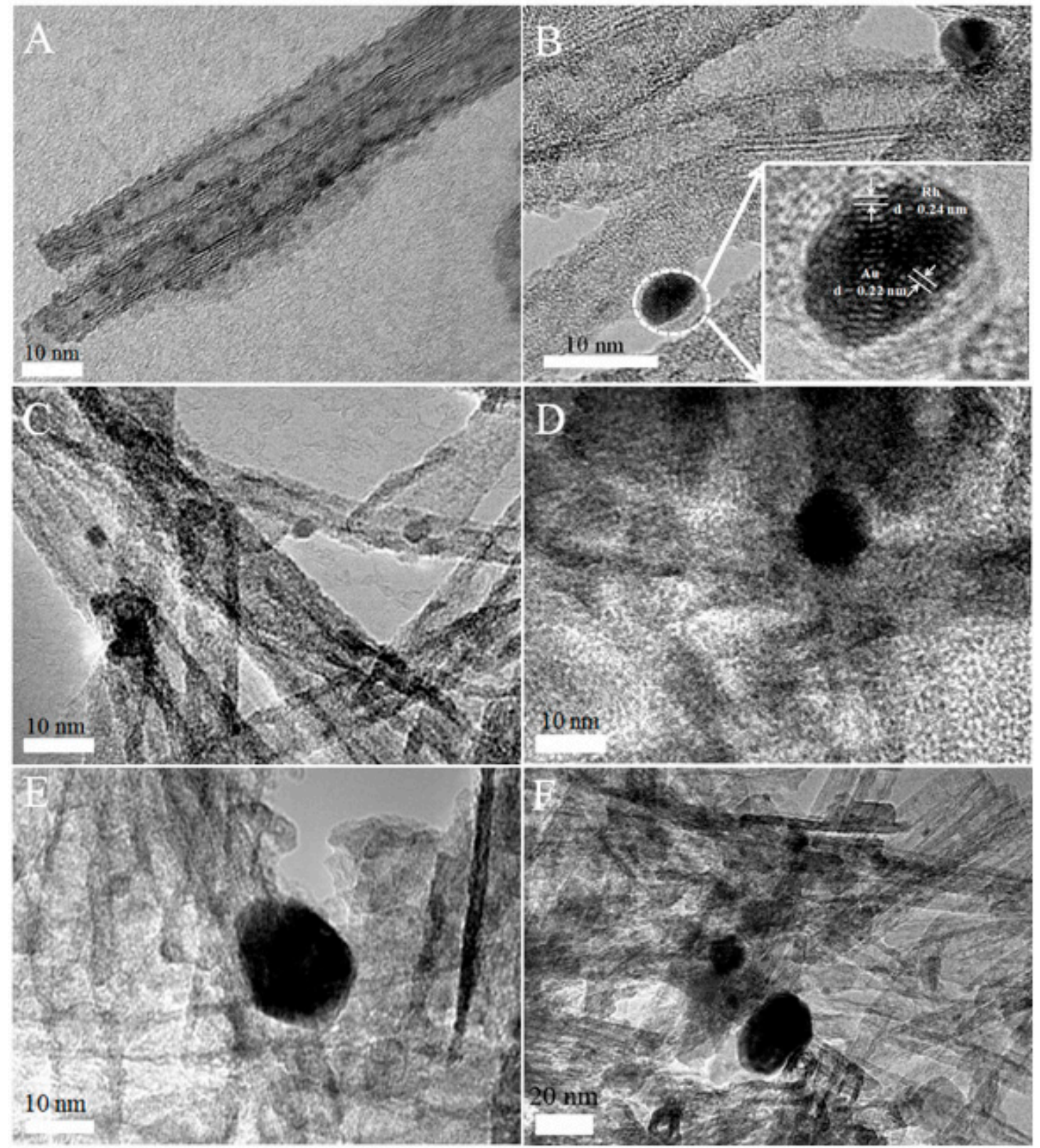

Figure 3. The TEM images of the resultant catalysts: $\mathrm{Rh}_{0.33} / \mathrm{TNTs}-1$ (A); $\mathrm{Au}_{0.52} / \mathrm{Rh}_{0.32} / \mathrm{TNTs}-12$ (B); $\mathrm{Rh}_{0.31} / \mathrm{Au}_{0.51} / \mathrm{TNT}-21 \quad$ (C); $\quad \mathrm{Au}_{0.49} / \mathrm{Rh}_{0.33} / \mathrm{TNTs}-22 \quad$ (D); $\mathrm{Au}_{0.50} / \mathrm{Rh}_{0.32} / \mathrm{TNTs}-11 \quad$ (E) and $\mathrm{Au}_{0.52} / \mathrm{Rh}_{0.32} / \mathrm{TNTs}-12 *(\mathbf{F})$.

As shown in Table 1 and Figure S2, the average particle sizes of both $\mathrm{Au}_{0.52} / \mathrm{Rh}_{0.32} / \mathrm{TNTs}-12$ (Entry 4 ) and $\mathrm{Rh}_{0.31} / \mathrm{Au}_{0.51} / \mathrm{TNTs}-21$ (Entry 9) are about $5 \mathrm{~nm}$. However, $\mathrm{Au}_{0.52} / \mathrm{Rh}_{0.32} / \mathrm{TNTs}-12$ contains a few larger metal particles compared to $\mathrm{Rh}_{0.31} / \mathrm{Au}_{0.51} / \mathrm{TNTs}-21$ (Figure $3 \mathrm{~B}, \mathrm{C}$ ). This indicates that the sequence of loading metals affects the size of the metal particles. Loading $\mathrm{Rh}$ first may result in catalysts producing smaller and more uniform metal particles. The TEM images of $\mathrm{Au}_{0.50} / \mathrm{Rh}_{0.32} / \mathrm{TNTs}-11$ (Figure 3E and Figure S1G) exhibit some larger particles $\left(18 \mathrm{~nm}\right.$ ) compared to that of $\mathrm{Au}_{0.49} / \mathrm{Rh}_{0.33} / \mathrm{TNTs}-22$ (Figure 3D and Figure S1F), while the two catalysts have a comparable average particle size (Table 1). This result should be related to the different reduction methods, which may result in different degrees of agglomeration of metals. The photo-reduction (method 1$)$ is a relatively intense and rapid reduction process, while the ethanol-reduction process (method 2) is mild and slow. As shown in Figure 3F and Figure $\mathrm{S} 1 \mathrm{H}$, after the calcination at $300{ }^{\circ} \mathrm{C}$, there is significantly more agglomeration of bimetallic 
species in $\mathrm{Au}_{0.52} / \mathrm{Rh}_{0.32} / \mathrm{TNTs}-12$. This probably results from the sintering effect [43] as the metal nanoparticles would melt and agglomerate in the process of calcination.

The TEM images display that different metal contents, reduction methods, sequence of loading metals and calcination affect the dispersion degree and particle size of the metal active species, which may subsequently affect the catalytic performance of the catalysts.

In order to investigate the chemical state of metals and the interactions of metals with supports and metals in catalysts, XPS analysis is performed on $\mathrm{Au}_{0.52} / \mathrm{Rh}_{0.32} / \mathrm{TNTs}-12$ and $\mathrm{Au}_{0.49} / \mathrm{Rh}_{0.33} / \mathrm{TNTs}-22$. The results are shown in Figure 4. Compared with the peaks of $\mathrm{Rh}^{0}\left(3 \mathrm{~d}_{5 / 2}=307.2 \mathrm{eV} ; 3 \mathrm{~d}_{3 / 2}=312.0 \mathrm{eV}\right)$ in the reported Rh/TNTs [42], the peaks of $\mathrm{Rh}^{0}$ in $\mathrm{Au}_{0.52} / \mathrm{Rh}_{0.32} / \mathrm{TNTs}-12$ and $\mathrm{Au}_{0.49} / \mathrm{Rh}_{0.33} / \mathrm{TNTs}-22$ (Figure $4 \mathrm{~A}, \mathrm{~B})$ shift to a lower $\mathrm{BE}$ value $\left(3 \mathrm{~d}_{5 / 2}=306.9 \mathrm{eV} ; 3 \mathrm{~d}_{3 / 2}=311.8 \mathrm{eV}\right)$. The characteristic photoelectron peaks of $\mathrm{Au} 4 \mathrm{f}$ in both catalysts are displayed in Figure 4C,D. The $\mathrm{Au}^{0}$ peaks in the two catalysts all shift to a higher $\mathrm{BE}$ value compared to the reported $\mathrm{Au} / \mathrm{TNTs}$ $\left(4 \mathrm{f}_{5 / 2}=87.6 \mathrm{eV} ; 4 \mathrm{f}_{7 / 2}=83.9 \mathrm{eV}\right)$ [44], which could be attributed to the interactions between $\mathrm{Rh}$ and $\mathrm{Au}[45,46]$. According to the negative shift of $\mathrm{Rh} 3 \mathrm{~d}$ and positive shift of $\mathrm{Au} 4 \mathrm{f}$ core-level peaks in bimetallic samples, it could be deduced that there are strong interactions between metals and support or metals and metals, which changes the electronic property of the metals in catalysts $[47,48]$. The peaks of oxidized rhodium in both Figure $3 \mathrm{~A}\left(3 \mathrm{~d}_{5 / 2}=308.3 \mathrm{eV} ; 3 \mathrm{~d}_{3 / 2}=331.2 \mathrm{eV}\right)$ and Figure $3 \mathrm{~B}$ $\left(3 \mathrm{~d}_{5 / 2}=308.2 \mathrm{eV} ; 3 \mathrm{~d}_{3 / 2}=331.2 \mathrm{eV}\right)$ are weak, which provides evidence that the majority of the two metals exist as $\mathrm{Rh}^{0}$ and $\mathrm{Au}^{0}$. The existence of the partial oxidation of $\mathrm{Rh}$ is possibly caused by the samples being exposed to air for a short time during the collection and weighing processes before the catalytic reaction. In addition, the peaks of $\mathrm{Au} 4 \mathrm{f}$ in $\mathrm{Au}_{0.49} / \mathrm{Rh}_{0.33} / \mathrm{TNTs}-22$ shift to a higher $\mathrm{BE}$ value compared with that in $\mathrm{Au}_{0.52} / \mathrm{Rh}_{0.32} / \mathrm{TNTs}-12$. This may be caused by the increased size of the metal particles, which affects the intensity of the interaction between metals [49], and these results are consistent with the TEM analysis.
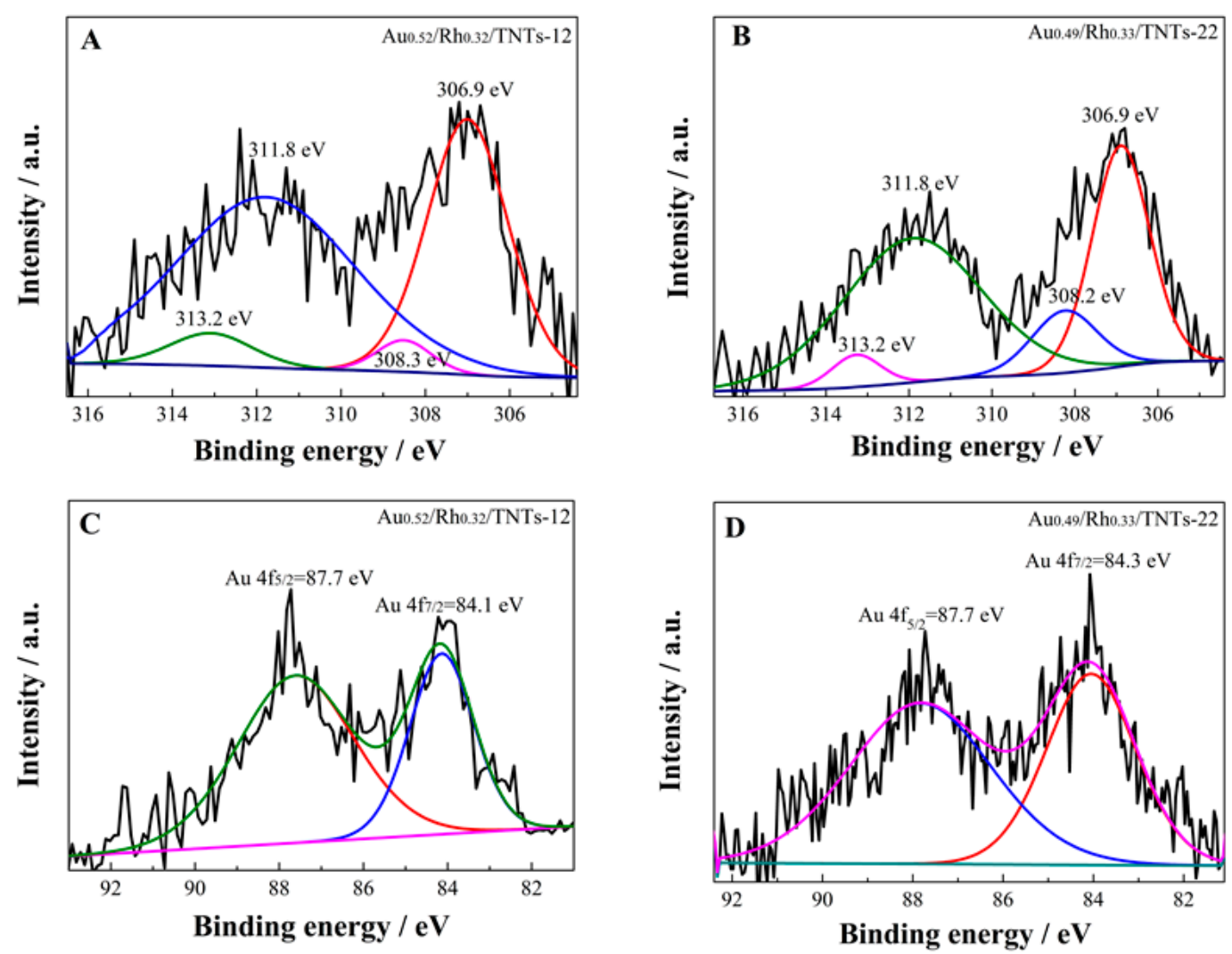

Figure 4. High-resolution XPS spectra of Rh 3d (A,B) and Au 4f (C,D) for the resultant materials. 
The $\mathrm{CO}$ absorption on the active sites of metals is an essential part of hydroformylation. As a $\pi$-acid ligand, $\mathrm{CO}$ is inclined to absorb on metals, which could provide more feedback electrons. During this process, the electrons partially transfer from a d-orbital of the metal to the anti-bonding CO molecular orbital. Figure 5 displays the FT-IR spectra of the adsorbed CO on the prepared samples at room temperature. Compared with $\mathrm{Rh}_{0.33} / \mathrm{TNTs}-1, \mathrm{Au}_{0.49} / \mathrm{TNTs}-2$ has an obvious peak of $\mathrm{CO}$ at $2066 \mathrm{~cm}^{-1}$, which could be attributed to the terminal CO adsorption on the metal. This means that CO tends to combine with $\mathrm{Au}$ [50], which is caused by the ability of Au to provide more feedback electrons to $\mathrm{CO}$ than Rh. In bimetallic samples, the CO peak decreased and shifted to $2060 \mathrm{~cm}^{-1}$ compared with that in monometallic Au catalyst. This may be related to the interactions between Rh and Au, which weakened the adsorption capacity of the catalyst to CO [51]. The band intensity of carbonyl vibration at $2060 \mathrm{~cm}^{-1}$ in $\mathrm{Au}_{0.52} / \mathrm{Rh}_{0.32} / \mathrm{TNTs}-12$ is higher than those in other bimetallic catalysts (Figure 5). This phenomenon could be attributed to the effect of metal particle size, which affects the interactions between $\mathrm{Rh}$ and $\mathrm{Au}$. In addition, the IR spectrum in $1750-1500 \mathrm{~cm}^{-1}$ is attributed to the bending vibration of $\mathrm{O}-\mathrm{H}$ bonds in $\mathrm{H}_{2} \mathrm{O}$ molecules, which are adsorbed on the surface of the TNT support [52]. Since there are different amounts of $\mathrm{H}_{2} \mathrm{O}$ molecules that may be adsorbed on the surface of the catalysts, the spectra of different samples may show some differences in the range of $1750-1500 \mathrm{~cm}^{-1}$.

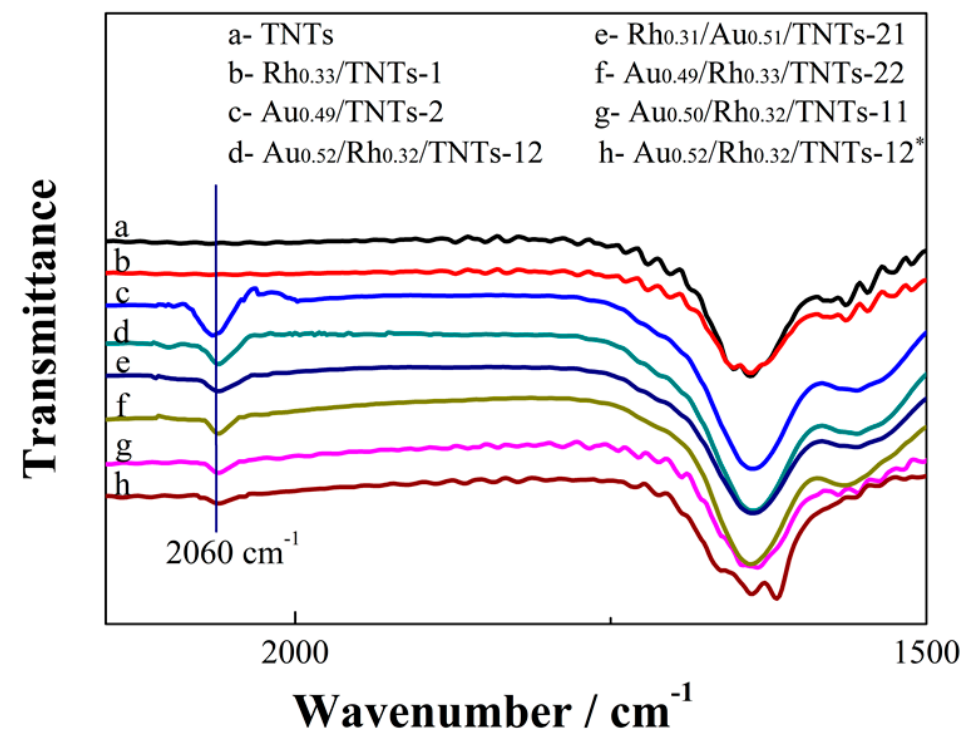

Figure 5. CO-FT-IR patterns of samples.

\subsection{Hydroformylation of Vinyl Acetate}

The schematic diagram of the vinyl acetate hydroformylation reaction is displayed in Scheme 1 and the proposal mechanism of bimetallic catalysts being involved in the hydroformylation of vinyl acetate is shown in Scheme 2. Under the experimental conditions in this work, 2-acetoxy propanal is the main product. To compare the selectivity of the reaction for aldehydes over different catalysts, all of the hydroformylation reactions lasted for $2 \mathrm{~h}$ although the conversion of vinyl acetate may not be complete. The reaction results for different catalysts under the same reaction conditions are listed in Table 2 .

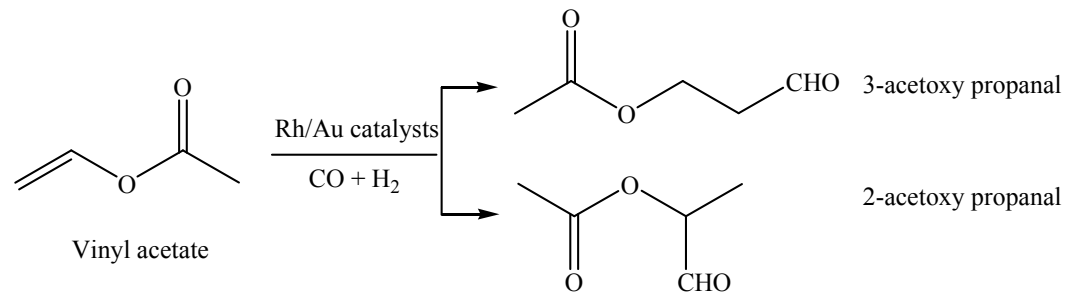

Scheme 1. Schematic diagram of vinyl acetate hydroformylation using prepared catalysts. 


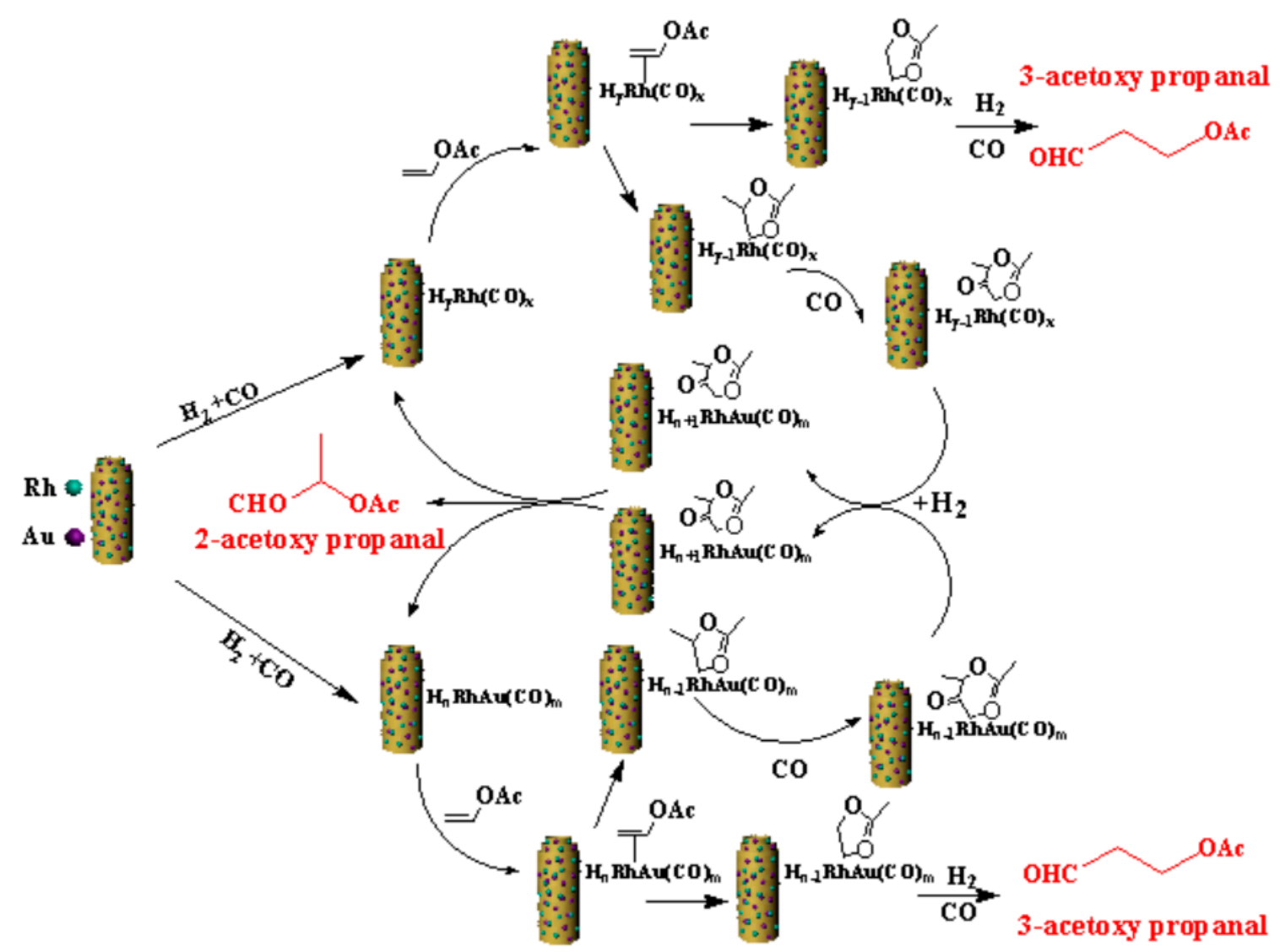

Scheme 2. Proposed mechanism for bimetallic catalysts being involved in the hydroformylation of vinyl acetate.

Table 2. Reaction results of vinyl acetate hydroformylation using prepared catalysts.

\begin{tabular}{cccccc}
\hline Entry & Catalysts & Conv. of Vinyl Acetate/\% & Selectivity for Ald./\% & b:1 & TOF/h \\
\hline 1 & $\mathrm{Rh}_{0.33} / \mathrm{TNTs}-1$ & 86.82 & 60.29 & 100 & 2210 \\
2 & $\mathrm{Rh}_{0.33} / \mathrm{TNTs}-2$ & 60.11 & 64.69 & 100 & 1640 \\
3 & $\mathrm{Au}_{0.49} / \mathrm{TNTs}-1$ & 0 & 0 & 0 & 0 \\
4 & $\mathrm{Au}_{0.49} / \mathrm{TNTs}-2$ & 0 & 0 & 0 & 0 \\
5 & $\mathrm{Au}_{0.28} / \mathrm{Rh}_{0.34} / \mathrm{TNTs}-12$ & 78.85 & 76.51 & 100 & 2460 \\
6 & $\mathrm{Au}_{0.52} / \mathrm{Rh}_{0.32} / \mathrm{TNTs}-12-\mathrm{U} 1$ & 88.11 & 88.67 & 100 & 3500 \\
7 & $\mathrm{Au}_{0.78} / \mathrm{Rh}_{0.31} / \mathrm{TNTs}-12$ & 36.67 & 70.00 & 100 & 1080 \\
8 & $\mathrm{Au}_{0.98} / \mathrm{Rh}_{0.33} / \mathrm{TNTs}-12$ & 32.47 & 59.74 & 100 & 870 \\
9 & $\mathrm{Au}_{0.49} / \mathrm{Rh}_{0.33} / \mathrm{TNTs}-22$ & 62.52 & 76.88 & 100 & 2020 \\
\hline 10 & $\mathrm{Au}_{0.50} / \mathrm{Rh}_{0.32} / \mathrm{TNTs}-11$ & 49.68 & 83.16 & 100 & 1800 \\
11 & $\mathrm{Rh}_{0.31} / \mathrm{Au}_{0.51} / \mathrm{TNTs}-21$ & 51.08 & 88.75 & 100 & 2030 \\
12 & $\mathrm{Au}_{0.52} / \mathrm{Rh}_{0.32} / \mathrm{TNTs}-12 *$ & 34.77 & 100 & 440 \\
13 & $\mathrm{Au}_{0.52} / \mathrm{Rh}_{0.32} / \mathrm{TNTs}-12-\mathrm{U} 2$ & 28.08 & 73.40 & 100 & 1700 \\
14 & $\mathrm{Au}_{0.52} / \mathrm{Rh}_{0.32} / \mathrm{TNTs}-12-\mathrm{U} 3$ & 51.73 & 47.86 & 100 & 750 \\
15 & $\mathrm{Rh}(\mathrm{acac})(\mathrm{CO})_{2}, 3.21$ mmol & 35.27 & 58.93 & 100 & 2200 \\
\hline
\end{tabular}

U: Circular reuse. In cycle experiments, the reaction mixture was transferred into the centrifugal tube for centrifugation. After this, the solids were washed by toluene for two times. After re-centrifugation, the catalyst was transferred into the reactor with $75 \mathrm{~mL}$ of toluene-vinyl acetate solution (65:10). (b:l): The ratio of branched aldehyde (2-acetoxy propanal) to linear aldehyde (3-acetoxy propanal). TOF: calculated by the formula TOF $=\frac{\mathrm{n}(\text { aldehydes })}{\mathrm{n}(\mathrm{Rh}) * \mathrm{~h}}$, where $n$ (aldehydes) is the total moles of aldehydes and $n(R h)$ is the total moles of $\mathrm{Rh}$ in the catalyst.

As shown in Table 2, when usingRh $\mathrm{Rh}_{0.33} / \mathrm{TNTs}-1$ (Entry 1) and $\mathrm{Rh}_{0.33} / \mathrm{TNTs}-2$ (Entry 2), the conversion of vinyl acetate is $86.82 \%$ and $60.11 \%$ while the selectivity for aldehydes is $60.29 \%$ and $64.69 \%$, respectively. Both monometallic catalysts $\mathrm{Au}_{0.49} / \mathrm{TNTs}-1$ (Entry 3 ) and $\mathrm{Au}_{0.49} / \mathrm{TNTs}-2$ 
(Entry 4) are catalytically inactive. This indicates that Rh species is the master catalytic species for the hydroformylation of vinyl acetate in this work. At the same time, photo-reduced Rh/TNTs has an advantage in the catalysis compared with the ethanol-reduced Rh/TNTs although they differ slightly in their selectivity for aldehydes. Compared with the $\mathrm{Rh}_{0.33} / \mathrm{TNTs}-1$ catalyst, bimetallic catalysts (Entry $5,6,7,9,10,11$ ) exhibit enhanced selectivity for aldehydes although the conversion of vinyl acetate differs greatly. Furthermore, $\mathrm{Au}_{0.98} / \mathrm{Rh}_{0.33} / \mathrm{TNTs}-12$ (Entry 8) shows poorer selectivity for aldehydes and poorer conversion of the substrate. This result demonstrates that the presence of an appropriate amount of $\mathrm{Au}$ in the catalysts is conducive to causing higher selectivity for aldehydes, while an excess amount of Au could have a negative impact on the reaction.

With an increase in Au content (Entry 5-8), the catalytic activity of $\mathrm{Au}_{\mathrm{x}} / \mathrm{Rh}_{\mathrm{y}} / \mathrm{TNTs}-12$ changes greatly. When the Au content varies from $0.28 \mathrm{wt} . \%$ to $0.52 \mathrm{wt} . \%$, TOF, the selectivity for aldehydes increases. However, when the content of $\mathrm{Au}$ increase from $0.52 \mathrm{wt} . \%$ to $0.98 \mathrm{wt} . \%$, both the TOF and selectivity for aldehydes decrease. The highest selectivity for aldehydes (88.67\%) and TOF $\left(3500 \mathrm{~h}^{-1}\right)$ are achieved at the $0.52 \mathrm{wt} . \%$ Au loading (Entry 6). This phenomenon may be due to the interactions between metals and the different sizes of the metal particles in the catalysts. When the mass fraction of $\mathrm{Au}$ is less than $0.52 \mathrm{wt} . \%$, with an increase in Au loading, the number of complex metal particles increase and they become highly dispersed on the support in smaller particles. This may provide more active sites for substrates and syngas to form mononuclear intermediates and binuclear intermediates, thus improving the chemical selectivity and the TOF value. However, when Au loading increases continuously past $0.52 \mathrm{wt} . \%$, there is a certain degree of agglomeration of the bimetal specie (TEM images and Table 1), which leads to larger particle sizes and a decrease in the exposed concentration of effective active sites for the hydroformylation reaction. Therefore, $0.52 \mathrm{wt} . \%$ Au should be the optimal loading.

In order to investigate the effect of the sequence of loading metals on the catalysis, the catalytic performance of $\mathrm{Rh}_{0.31} / \mathrm{Au}_{0.51} / \mathrm{TNTs}-21$ (Entry 11) is contrasted with that of $\mathrm{Au}_{0.52} / \mathrm{Rh}_{0.32} / \mathrm{TNTs}-12$ (Entry 6). With comparable metal contents and SSA, the two catalysts show comparative selectivity for aldehydes but great differences in their conversion of vinyl acetate. $\mathrm{Au}_{0.52} / \mathrm{Rh}_{0.32} / \mathrm{TNTs}-12$ exhibits superior activity to $\mathrm{Rh}_{0.31} / \mathrm{Au}_{0.51} / \mathrm{TNTs}-21$, which may result from the advantages of anchoring $\mathrm{Rh}$ first in terms of the dispersion of two metals and exposure of more active sites for hydroformylation.

Compared with $\mathrm{Rh}_{0.33} / \mathrm{TNTs}-1$, both $\mathrm{Au}_{0.52} / \mathrm{Rh}_{0.32} / \mathrm{TNTs}-12$ (Entry 6) and $\mathrm{Au}_{0.50} / \mathrm{Rh}_{0.32} / \mathrm{TNTs}-11$ (Entry 10) exhibit excellent selectivity for aldehydes albeit great differences in conversion of the substrate. This result could be caused by the fact that the presence of Au effectively improved the selectivity for aldehydes. However, different reduction methods of Au result in different degrees of metal agglomeration, which could also be seen in TEM images. $\mathrm{Au}_{0.49} / \mathrm{Rh}_{0.33} / \mathrm{TNTs}-22$ (Entry 9) shows apparently higher selectivity $(76.88 \%)$ for aldehydes than that of $\mathrm{Rh}_{0.33} / \mathrm{TNTs}-2(64.69 \%)$ with a comparable conversion of vinyl acetate. This provides further evidence that the presence of $\mathrm{Au}$ enhanced the selectivity for aldehydes in the hydroformylation of vinyl acetate and there is synergism between the two metals. On the other hand, the conversion of the substrate using $\mathrm{Au}_{0.49} / \mathrm{Rh}_{0.33} / \mathrm{TNTs}-22$ and $\mathrm{Au}_{0.50} / \mathrm{Rh}_{0.32} / \mathrm{TNTs}-11$ is lower than that achieved using $\mathrm{Au}_{0.52} / \mathrm{Rh}_{0.32} / \mathrm{TNTs}-12$. The different particle sizes of the metal components, SSA and intensities of the interaction between the metals may account for this phenomenon, which is shown in Table 1 as well as in XPS analysis. The agglomeration of metals, which results in different sizes of metal particles, can lead to a decrease in the exposed concentration of metals and different interactions between metals in the catalysts. The decrease in SSA may cause a reduction in the contact area between the substrate and catalyst. Therefore, the catalysts show great differences in their conversion of vinyl acetate.

After calcination, $\mathrm{Au}_{0.52} / \mathrm{Rh}_{0.32} / \mathrm{TNTs}-12$ (Entry 12) exhibits poor catalytic performance. This may be caused by the severe agglomeration of its bimetallic species, which probably results from the calcination process. During this process, the metal nanoparticles would melt and agglomerate under high temperatures. 
$\mathrm{Au}_{0.52} / \mathrm{Rh}_{0.32} / \mathrm{TNTs}-12$ was used for cycle experiments to investigate the recycling performance of the resultant samples, the results of which are shown in Table 2 (Entry 6,13 and 14). In the second cycle, the conversion rate of vinyl acetate decreased to $51.73 \%$, while the selectivity for aldehydes $(73.40 \%)$ was still higher than that of $\mathrm{Rh}_{0.33} / \mathrm{TNTs}-1$ (60.29\%). After three cycles, both the substrate conversion and the selectivity for aldehydes decreased dramatically, while the TOF also decreased to $760 \mathrm{~h}^{-1} . \mathrm{Rh}$ and $\mathrm{Au}$ contents in $\mathrm{Au}_{0.52} / \mathrm{Rh}_{0.32} / \mathrm{TNTs}-12$ after three cycles are $0.16 \mathrm{wt} . \%$ and $0.28 \mathrm{wt} . \%$, respectively, which were measured by ICP. Therefore, it can be deduced that the decrease in catalytic activity in cycle reactions is caused by the partial loss of $\mathrm{Rh}$ and Au nanoparticles. During the reaction, the metal species could interact with the substrate or syngas, which may cause the metal nanoparticles to fall off the support and dissolve in the reaction system. Rh/TNTs- 1 and $\mathrm{Rh}(\mathrm{acac})(\mathrm{CO})_{2}$ exhibits commensurable TOF with an equal metal mass. However, after one cycle, Rh content in Rh/TNTs-1 is $0.15 \mathrm{wt} . \%$. This could be attributed to the limiting effect of TNTs, which has a long tubular structure to prevent the loss of metals. On the other hand, Rh content in Rh/TNTs- 1 after the reaction (0.15 wt.\%) is lower than that in $\mathrm{Au}_{0.52} / \mathrm{Rh}_{0.32} / \mathrm{TNTs}-12$ after three cycles $(0.16 \mathrm{wt} . \%)$. Based on this case, we could be deduced that the interactions between Rh and Au may play a role in preventing metal loss.

\section{Materials and Methods}

All reagents used were purchased from commercial suppliers and without any further purification. $\mathrm{CO}, \mathrm{H}_{2}, \mathrm{~N}_{2}$ and Ar used were all of $99.99 \%$ purity.

\subsection{Preparation of the Catalysts}

The TNTs were synthesized by a hydrothermal method based on a previous work [23]. Titanium dioxide was mixed with an aqueous $\mathrm{NaOH}$ solution, before the system was heated to $150{ }^{\circ} \mathrm{C}$ for $12 \mathrm{~h}$ with constant stirring. After washing with water, the TNTs were prepared using an acidification and drying process. The Au-Rh/TNTs catalysts were prepared via an impregnation-reduction (method $\mathrm{a}, \mathrm{a}=1$ or 2 )-impregnation-reduction (method $\mathrm{b}, \mathrm{b}=1$ or 2 ) procedure. The impregnation processes are described as follows. $1 \mathrm{~g}$ TNTs was dispersed into $\mathrm{RhCl}_{3}(0.0020 \mathrm{~g} / \mathrm{mL}, \mathrm{V}=1.750 \mathrm{~mL})$ or $\mathrm{HAuCl}_{4}(0.0100 \mathrm{~mol} / \mathrm{L}, \mathrm{V}=0.625 \mathrm{~mL}, 1.250 \mathrm{~mL}, 1.875 \mathrm{~mL}$ and $2.500 \mathrm{~mL})$ solution. After being vigorously stirred for $12 \mathrm{~h}$ and undergoing ultrasonic dispersion for $2 \mathrm{~h}$, the mixture was centrifuged and the solid was collected and washed with water. Two reduction procedures were used to reduce the solid.

Photo-reduction (Method 1): The solid obtained was dispersed into $50 \mathrm{~mL}$ of ethanol-water solution (9:1) in a 60-mL quartz reactor and irradiated under UV light with a 300-W mercury lamp for $4 \mathrm{~h}$ with stirring.

Ethanol-reduction (Method 2): The solid obtained was dispersed into $50 \mathrm{~mL}$ of ethanol-water solution (9:1) in a 100-mL three-neck flask and refluxed for $6 \mathrm{~h}$ in argon atmosphere with vigorous stirring.

The obtained catalysts were labeled as $\mathrm{M}_{\mathrm{x}} / \mathrm{M}_{\mathrm{y}}^{\prime} / \mathrm{TNTs}-\mathrm{ab}$, where $\mathrm{M}^{\prime}$ was impregnated and reduced by method a firstly, before $\mathrm{M}$ was impregnated and reduced by method $\mathrm{b}$ in the preparation procedure. Furthermore, $\mathrm{x}$ and $\mathrm{y}$ were the mass fractions of $\mathrm{M}$ and $\mathrm{M}^{\prime}$ in the catalyst, respectively. For example, $\mathrm{Au}_{0.52} / \mathrm{Rh}_{0.32} / \mathrm{TNTs}-12$ meant that $\mathrm{Rh}(0.33 \mathrm{wt} . \%)$ was anchored to the TNTs by impregnation and photo-reduction, before $\mathrm{Au}(0.52 \mathrm{wt} . \%)$ was immobilized to $\mathrm{Rh}_{0.33} / \mathrm{TNTs}-1$ by impregnation and ethanol-reduction. In addition, the corresponding monometallic catalysts $\left(\mathrm{Rh}_{0.33} / \mathrm{TNTs}-1\right.$, $\mathrm{Rh}_{0.33} / \mathrm{TNTs}-2, \mathrm{Au}_{0.49} / \mathrm{TNTs}-1$ and $\left.\mathrm{Au}_{0.49} / \mathrm{TNTs}-2\right)$ were also synthesized for comparative purposes.

The preparation procedure of the catalysts is illustrated in Scheme 3. 


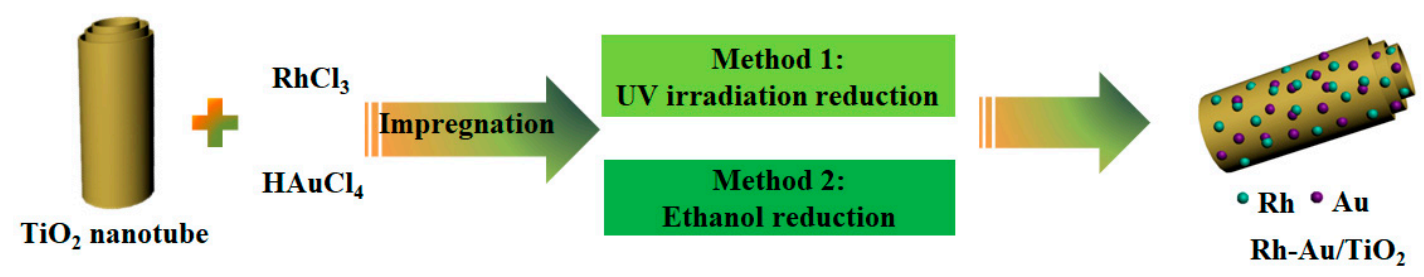

Scheme 3. Preparation procedure of the catalysts.

\subsection{Hydroformylation of Vinyl Acetate}

The hydroformylation of vinyl acetate was carried out in a $250-\mathrm{mL}$ stainless steel autoclave reactor equipped with a magnetic stirrer. After adding toluene $(65 \mathrm{~mL})$, vinyl acetate $(10 \mathrm{~mL})$ and catalysts $(0.4000 \mathrm{~g})$, the reactor was sealed and purged with hydrogen three times to eliminate air, before being pressurized to $6 \mathrm{MPa}$ with $\mathrm{CO} / \mathrm{H}_{2}\left(\mathrm{n}_{\mathrm{CO}} / \mathrm{n}_{\mathrm{H} 2}=1\right)$ with stirring at room temperature. After this, the reactor was heated to $100{ }^{\circ} \mathrm{C}$ with stirring and kept for $2 \mathrm{~h}$ at $100{ }^{\circ} \mathrm{C}$. The reactor was subsequently cooled to room temperature and depressurized to atmospheric pressure. The products were analyzed with a gas chromatograph (Shimadzu GC-2014) equipped with a SE-30 capillary column $(30 \mathrm{~m} \times 0.53 \mathrm{~mm} \times 1.0 \mu \mathrm{m})$ and a FID detector. The internal standard used was 3-pentanone, while nonane was the solvent. The gas chromatogram of vinyl acetate hydroformylation is given in Figure S3. The retention times of n-propanal, 3-pentanone, 2-acetoxy propanal and 3-acetoxy propanal are $1.316 \mathrm{~min}, 3.025 \mathrm{~min}, 5.671 \mathrm{~min}$ and $7.848 \mathrm{~min}$, respectively.

\subsection{Characterization}

Powder X-ray diffraction (XRD) patterns were gathered on a Rigaku D/Max-2500 X-ray diffractometer. Metal contents were measured by Varian 725-ES Inductively coupled plasma mass spectrometer (ICP). The specific surface area (SSA) was determined by $\mathrm{N}_{2}$ adsorption at $-196{ }^{\circ} \mathrm{C}$ using a Nova 2000e surface area analyzer (Quantachrome). The samples were degassed under vacuum at $200{ }^{\circ} \mathrm{C}$ for $3 \mathrm{~h}$ before measurement. Transmission electron microscopy (TEM) and energy dispersive X-ray spectroscopy (EDX) were conducted on a JEM-2010FEF transmission electron microscope. X-ray photoelectron spectroscopy (XPS) was carried out using Al X-ray source (Al Ka-150 W, Kratos Axia Ultra DLA), while the binding energy was calibrated by taking the1s peak of $C$ at $284.6 \mathrm{eV}$ as the reference. The infrared spectra of $\mathrm{CO}$ adsorption were collected on a Bio-Rad FTS6000 spectrophotometer ( $\mathrm{KBr}$ pellets). Before the measurement, the samples were placed in a sealed 250-mL stainless steel autoclave reactor pressurized with CO (3 MPa) for $4 \mathrm{~h}$.

\section{Conclusions}

The anatase $\mathrm{TiO}_{2}$ nanotube-supported $\mathrm{Rh}$ and Au bimetallic species of different Au contents are synthesized via different reduction methods and sequences of loading metals. The characterization results show that the addition of gold can significantly enhance the adsorption of $\mathrm{CO}$ and some of the gold species formed complex metal particles with Rh. The catalytic results show that the presence of gold can make effects on the selectivity for aldehydes in the vinyl acetate hydroformylation. However, excess Au loading results in a decrease in the vinyl acetate conversion and the selectivity for aldehydes. Furthermore, different reduction methods and sequences of loading metals lead to the variability of particle sizes of the bimetallic species, which could potentially have an impact on the catalytic reaction. Among the prepared samples, $\mathrm{Au}_{0.52} / \mathrm{Rh}_{0.32} / \mathrm{TNTs}-12$ catalyst exhibits the highest catalytic activity, with the accompanying selectivity for aldehydes and TOF value being $88.67 \%$ and $3500 \mathrm{~h}^{-1}$, respectively. After the second cycle, the selectivity for aldehydes and TOF value decreased to $73.40 \%$ and $1700 \mathrm{~h}^{-1}$ when using $\mathrm{Au}_{0.52} / \mathrm{Rh}_{0.32} / \mathrm{TNTs}-12$ catalyst, which means that a considerable amount of effort is needed to improve the cycle performance of the catalysts.

Supplementary Materials: The following are available online at http:/ /www.mdpi.com/2073-4344/8/10/420/s1, Figure S1: TEM of catalysts: TNTs (A), $\mathrm{Au}_{0.49} / \mathrm{TNTs}-2$ (B), $\mathrm{Au}_{0.28} / \mathrm{Rh}_{0.34} / \mathrm{TNTs}-12$ (C), $\mathrm{Au}_{0.78} / \mathrm{Rh}_{0.31} / \mathrm{TNTs}-12$ (D), 
$\mathrm{Au}_{0.98} / \mathrm{Rh}_{0.33} / \mathrm{TNTs}-12$ (E), $\mathrm{Au}_{0.49} / \mathrm{Rh}_{0.33} / \mathrm{TNTs}-22$ (F), Au $\mathrm{Au}_{0.50} / \mathrm{Rh}_{0.32} / \mathrm{TNTs}-11$ (G) and $\mathrm{Au}_{0.52} / \mathrm{Rh}_{0.32} / \mathrm{TNTs}-12^{*}$ $(\mathrm{H})$, Figure S2: Particle size distribution of the resultant catalysts, Figure S3: Gas chromatogram of vinyl acetate hydroformylation.

Author Contributions: Conceptualization, W.H. and Y.C.; Methodology, Y.C.; Software, Y.C.; Validation, W.H., S.Z. and B.Z.; Formal Analysis, X.L.; Investigation, Y.C.; Resources, W.H.; Data Curation, H.L.; Writing-Original Draft Preparation, Y.C.; Writing-Review \& Editing, Y.C.; Visualization, P.S.; Supervision, W.H.; Project Administration, W.H.; Funding Acquisition, W.H.

Funding: This research was funded by [National Natural Science Foundation of China] grant number 21373120 and 21071086; [111 Project] grant number B12015.

Conflicts of Interest: The authors declare no conflict of interest.

\section{References}

1. Rodrigues, C.; Delolo, F.G.; Norinder, J.; Börner, A.; Bogado, A.L.; Batista, A.A. Hydroformylation-hydrogenation and hydroformylation-acetalization reactions catalyzed by ruthenium complexes. J. Mol. Catal. A Chem. 2017, 426, 586-592.

2. Deng, Y.C.; Wang, H.; Sun, Y.H.; Wang, X. Principles and applications of enantioselective hydroformylation of terminal disubstituted alkenes. ACS Catal. 2015, 5, 6828-6837.

3. Ganga, V.S.R.; Dabbawala, A.A.; Munusamy, K.; Abdi, S.H.R.; Kureshy, R.I.; Khan, N.U.H.; Bajaj, H.C. Rhodium complexes supported on nanoporous activated carbon for selective hydroformylation of olefins. Catal. Commun. 2016, 84, 21-24.

4. Chikkali, S.H.; van der Vlugt, J.I.; Reek, J.N.H. Hybrid diphosphorus ligands in rhodium catalysed asymmetric hydroformylation. Coord. Chem. Rev. 2014, 262, 1-15.

5. Franke, R.; Selent, D.; Borner, A. Applied Hydroformylation. Chem. Rev. 2012, 112, 5675-5732. [CrossRef] [PubMed]

6. Pandey, S.; Raj, K.V.; Shinde, D.R.; Vanka, K.; Kashyap, V.; Kurungot, S.; Vinod, C.P.; Chikkali, S.H. Iron catalyzed hydroformylation of alkenes under mild conditions: Evidence of an Fe(II) catalyzed process. J. Am. Chem. Soc. 2018, 140, 4430-4439. [PubMed]

7. Kamper, A.; Kucmierczyk, P.; Seidensticker, T.; Vorholt, A.J.; Andreas, J.; Franke, R.; Behr, A. Ruthenium-catalyzed hydroformylation: From laboratory to continuous miniplant scale. Catal. Sci. Technol. 2016, 6, 8072-8079. [CrossRef]

8. Liu, D.P.; Chaudhari, R.V.; Subramaniam, B. Homogeneous catalytic hydroformylation of propylene in propane-expanded solvent media. Chem. Eng. Sci. 2018, 187, 148-156.

9. Wang, Y.Q.; Yan, L.; Li, C.Y.; Jiang, M.; Wang, W.L.; Ding, Y.J. Highly efficient porous organic copolymer supported Rh catalysts for heterogeneous hydroformylation of butenes. Appl. Catal. A Gen. 2018, 551, 98-105.

10. Zhao, Y.P.; Zhang, X.M.; Sanjeevi, J.; Yang, Q.H. Hydroformylation of 1-octene in pickering emulsion constructed by amphiphilic mesoporous silica nanoparticles. J. Catal. 2016, 334, 52-59.

11. Mormul, J.; Breitenfeld, J.; Trapp, O.; Paciello, R.; Schaub, T.; Hofmann, P. Synthesis of adipic acid, 1,6-hexanediamine, and 1,6-hexanediol via double-n-selective hydroformylation of 1,3-butadiene. ACS Catal. 2016, 6, 2802-2810. [CrossRef]

12. Li, C.Y.; Wang, W.L.; Yan, L.; Ding, Y.J. A mini review on strategies for heterogenization of rhodium-based hydroformylation catalysts. Front. Chem. Sci. Eng. 2018, 12, 113-123. [CrossRef]

13. Weiss, A.; Munoz, M.; Haas, A.; Rietzler, F.; Steinruck, H.P.; Haumann, M.; Wasserscheid, P.; Etzold, B.J.M. Boosting the activity in supported ionic liquid-phase-catalyzed hydroformylation via surface functionalization of the carbon support. ACS Catal. 2016, 6, 2280-2286. [CrossRef]

14. Zhang, H.; Li, Y.Q.; Wang, P.; Lu, Y.; Zhao, X.L.; Liu, Y. Effect of positive-charges in diphosphino-imidazolium salts on the structures of Ir-complexes and catalysis for hydroformylation. J. Mol. Catal. A-Chem. 2015, 411, 337-343. [CrossRef]

15. Whiteker, G.T.; Cobley, C.J. Applications of Rhodium-catalyzed hydroformylation in the pharmaceutical, agrochemical, and fragrance industries. Topics Organomet. Chem. 2012, 42, 35-46.

16. Yuki, Y.; Takahashi, K.; Tanaka, Y.; Nozaki, K. Tandem isomerization/hydroformylation/hydrogenation of internal alkenes to n-alcohols using $\mathrm{Rh} / \mathrm{Ru}$ dual- or ternary-catalyst systems. J. Am. Chem. Soc. 2013, 135, 17393-17400. [CrossRef] [PubMed] 
17. Alsalahi, W.; Trzeciak, A.M. “On water” hydroformylation of 1-hexene using Rh/PAA (PAA = polyacrylic acid) as catalyst. RSC Adv. 2014, 4, 30384-30391. [CrossRef]

18. Vunain, E.; Ncube, P.; Jalama, K.; Meijboom, R. Confinement effect of rhodium(I) complex species on mesoporous MCM-41 and SBA-15: Effect of pore size on the hydroformylation of 1-octene. J. Porous Mat. 2018, 25, 303-320. [CrossRef]

19. Tan, M.H.; Wang, D.; Ai, P.P.; Liu, G.G.; Wu, M.B.; Zheng, J.T.; Yang, G.H.; Yoneyama, Y.; Tsubaki, N. Enhancing catalytic performance of activated carbon supported Rh catalyst on heterogeneous hydroformylation of 1-hexene via introducing surface oxygen-containing groups. Appl. Catal. A Gen. 2016, 527, 53-59. [CrossRef]

20. Sun, Q.; Dai, Z.F.; Liu, X.L.; Sheng, N.; Deng, F.; Meng, X.J.; Xiao, F.S. Highly efficient heterogeneous hydroformylation over Rh-metalated porous organic polymers: Synergistic effect of high ligand concentration and flexible framework. J. Am. Chem. Soc. 2015, 137, 5204-5209. [CrossRef] [PubMed]

21. Ma, Y.B.; Gao, Z.X.; Yuan, T.; Wang, T.F. Kinetics of dicyclopentadiene hydroformylation over $\mathrm{Rh}-\mathrm{SiO}_{2}$ catalysts. Prog. React. Kinet. Mech. 2017, 42, 191-199. [CrossRef]

22. Hou, C.; Zhao, G.F.; Ji, Y.J.; Niu, Z.Q.; Wang, D.S.; Li, Y.D. Hydroformylation of alkenes over rhodium supported on the metal-organic framework ZIF-8. Nano Res. 2014, 7, 1364-1369. [CrossRef]

23. Hu, X.J.; Shi, Y.K.; Zhang, Y.J.; Zhu, B.L.; Zhang, S.M.; Huang, W.P. Nanotubular $\mathrm{TiO}_{2}$-supported amorphous Co-B catalysts and their catalytic performances for hydroformylation of cyclohexene. Catal. Commun. 2015, 59, 45-49. [CrossRef]

24. Shi, Y.K.; Hu, X.J.; Chen, L.; Lu, Y.; Zhu, B.L.; Zhang, S.M.; Huang, W.P. Boron modified $\mathrm{TiO}_{2}$ nanotubes supported Rh-nanoparticle catalysts for highly efficient hydroformylation of styrene. New J. Chem. 2017, 41, 6120-6126. [CrossRef]

25. Gual, A.; Godard, C.; Castillon, S.; Claver, C. Highly efficient Rhodium catalysts for the asymmetric hydroformylation of vinyl and allyl ethers using C1-symmetrical diphosphite ligands. Adv. Synth. Catal. 2010, 352, 463-477. [CrossRef]

26. Khan, S.R.; Bhanage, B.M. Regioselectivehydroformylation of vinyl esters catalyzed by $\mathrm{Rh}(\mathrm{acac})(\mathrm{CO})_{2}$ with simple and efficient diphosphinite ligands. Catal. Commun. 2014, 46, 109-112. [CrossRef]

27. Tada, M.; Motokura, K.; Iwasawa, Y. Conceptual integration of homogeneous and heterogeneous catalyses. Top. Catal. 2008, 48, 32-40. [CrossRef]

28. Garlaschelli, L.; Marchionna, M.; Iapalucci, M.C.; Longoni, G. Hydroformylation and hydrocarbonylation of dicyclopentadiene with cobalt-rhodium catalytic systems promoted by triphenylphosphine: Synthesis of monoformyltricyclodecenes, diformyltricyclodecanes and di(tricyclodecenyl)ketones. J. Mol. Catal. 1991, 68, 7-21. [CrossRef]

29. Martin, B.; Warner, D.K.; Norton, J. Mechanism of the reaction of a solvated Rhenium acyl complex with neutral transition-metal hydrides. Relative nucleophilicity of such hydrides. J. Am. Chem. Soc. 1986, 108, 33-39. [CrossRef]

30. Renaut, P.; Tainturier, G.; Gautheron, B. Formation of a zirconium-molybdenum bond via methane elimination. J. Organomet. Chem. 1978, 150, C9-C10. [CrossRef]

31. Ma, Y.B.; Fu, J.; Gao, Z.X.; Zhang, L.B.; Li, C.Y.; Wang, T.F. Dicyclopentadiene Hydroformylation to Value-Added Fine Chemicals over Magnetically Separable $\mathrm{Fe}_{3} \mathrm{O}_{4}$-Supported Co-Rh Bimetallic Catalysts: Effects of Cobalt Loading. Catalysts 2017, 7, 103. [CrossRef]

32. Buchwalter, P.; Rose, J.; Braunstein, P. Multimetallic catalysis based on heterometallic complexes and clusters. Chem. Rev. 2015, 115, 28-126. [CrossRef] [PubMed]

33. Hetterscheid, D.G.H.; Chikkali, S.H.; de Bruin, B.; Reek, J.N.H. Binuclear cooperative catalysts for the hydrogenation and hydroformylation of olefins. ChemcatChem 2013, 5, 2785-2793. [CrossRef]

34. Li, C.Z.; Chen, L.; Widjaja, E.; Garland, M. The catalytic binuclear elimination reaction: Confirmation from in situ FTIR studies of homogeneous rhodium catalyzed hydroformylation. Catal. Today 2010, 155, 261-265. [CrossRef]

35. Li, C.Z.; Gao, F.; Cheng, S.Y.; Tjahjono, M.; van Meurs, M.; Tay, B.Y.; Jacob, C.; Guo, L.F.; Garland, M. From stoichiometric to catalytic binuclear elimination in Rh-W hydroformylations. Identification of two new heterobimetallic intermediates. Organometallics 2011, 30, 4292-4296. [CrossRef]

36. Klahn, M.; Garland, M.V. On the mechanism of the catalytic binuclear elimination reaction in hydroformylation systems. ACS Catal. 2015, 5, 2301-2316. [CrossRef] 
37. Sudarsanam, P.; Mallesham, B.; Reddy, P.S.; Grossmann, D.; Grunert, W.; Reddy, B.M. Nano-Au/CeO 2 catalysts for $\mathrm{CO}$ oxidation: Influence of dopants (Fe, $\mathrm{La}$ and $\mathrm{Zr}$ ) on the physicochemical properties and catalytic activity. Appl. Catal. B-Environ. 2014, 144, 900-908. [CrossRef]

38. Bulushev, D.A.; Zacharska, M.; Guo, Y.N.; Beloshapkin, S.; Simakov, A. CO-free hydrogen production from decomposition of formic acid over $\mathrm{Au} / \mathrm{Al}_{2} \mathrm{O}_{3}$ catalysts doped with potassium ions. Catal. Commun. 2017, 92, 86-89. [CrossRef]

39. Cao, R.B.; Xia, T.T.; Zhu, R.Z.; Liu, Z.H.; Guo, J.M.; Chang, G.; Zhang, Z.L.; Liu, X.; He, Y.B. Novel synthesis of core-shell Au-Pt dendritic nanoparticles supported on carbon black for enhanced methanol electro-oxidation. Appl. Surf. Sci. 2018, 433, 840-846. [CrossRef]

40. Ma, Y.B.; Qing, S.J.; Gao, Z.X.; Mamat, X.; Zhang, J.; Li, H.Y.; Eli, W.M.J. Tandem hydroformylation and hydrogenation of dicyclopentadiene by $\mathrm{Co}_{3} \mathrm{O}_{4}$ supported gold nanoparticles. Catal. Sci. Technol. 2015, 5, 3649-3657. [CrossRef]

41. Chuai, H.Y.; Liu, X.T.; Chen, Y.; Zhu, B.L.; Zhang, S.M.; Huang, W.P. Hydroformylation of vinyl acetate and cyclohexene over $\mathrm{TiO}_{2}$ nanotube supported $\mathrm{Rh}$ and $\mathrm{Ru}$ nanoparticle catalysts. RSC Adv. 2018, 8, 12053-12059. [CrossRef]

42. Shi, Y.K.; Hu, X.J.; Zhu, B.L.; Wang, S.R.; Zhang, S.M.; Huang, W.P. Synthesis and characterization of $\mathrm{TiO}_{2}$ nanotube supported Rh-nanoparticle catalysts for regioselectiovehydroformylation of vinyl acetate. RSC Adv. 2014, 4, 62215-62222. [CrossRef]

43. Liu, J.X.; Qiao, B.T.; Song, Y.; Tang, H.L.; Huang, Y.D.; Liu, J.Y. Highly active and sintering-resistant heteroepitaxy of Au nanoparticles on $\mathrm{ZnO}$ nanowires for CO oxidation. J. Energy Chem. 2016, 25, 361-370. [CrossRef]

44. Zhao, H.; Zhang, P.; Wang, Y.D.; Huang, W.P.; Zhang, S.M. Au/ $\mathrm{TiO}_{2}$ nanotube catalysts prepared by combining sol-gel method with hydrothermal treatment and their catalytic properties for $\mathrm{CO}$ oxidation. J. Sol.-Gel. Sci. Technol. 2014, 71, 406-412. [CrossRef]

45. Wang, S.H.; Xin, Z.L.; Huang, X.; Yu, W.Z.; Niu, S.; Shao, L.D. Nanosized Pd-Au bimetallic phases on carbon nanotubes for selective phenylacetylene hydrogenation. Phys. Chem. Chem. Phys. 2017, 19, 6164-6168. [CrossRef] [PubMed]

46. Chen, X.L.; Yang, G.M.; Feng, S.P.; Shi, L.; Huang, A.L.; Pan, H.B.; Liu, W. Au@AuPt nanoparticles embedded in B-doped graphene: A superior electrocatalyst for determination of rutin. Appl. Surf. Sci. 2017, 402, 232-244. [CrossRef]

47. Zhang, P.; Yu, H.H.; Li, J.J.; Zhao, H.; Zhu, B.L.; Huang, W.P.; Zhang, S.M. Au/BiPO 4 nanorod catalysts: Synthesis, characterization and their catalytic performance for CO oxidation. RSC Adv. 2016, 6, 15304-15312. [CrossRef]

48. Sareen, S.; Mutreja, V.; Pal, B.; Singh, S. Synthesis of bimetallic Au-Ag alloyed mesocomposites and their catalytic activity for the reduction of nitroaromatics. Appl. Surf. Sci. 2018, 435, 552-562. [CrossRef]

49. Berko, A.; Ulrych, I.; Prince, K.C. Encapsulation of Rh nanoparticles supported on $\mathrm{TiO}_{2}(110)-(1 \times 1)$ surface: XPS and STM studies. J. Phys. Chem. B 1998, 102, 3379-3386. [CrossRef]

50. Chang, B.K.; Jang, B.W.; Dai, S.; Overbury, S.H. Transient studies of the mechanisms of CO oxidation over Au/TiO2 using time-resolved FTIR spectroscopy and product analysis. J. Catal. 2005, 236, 392-400. [CrossRef]

51. Calzada, L.A.; Collins, S.E.; Han, C.W.; Ortalan, V.; Zanella, R. Synergetic effect of bimetallic $\mathrm{Au}-\mathrm{Ru} / \mathrm{TiO}_{2}$ catalysts for complete oxidation of methanol. Appl. Catal. B-Environ. 2017, 207, 79-92. [CrossRef]

52. Zhang, S.H.; Han, X.X. Study on preparation and morphology of Aluminum-coated titanium dioxide. Semicond. Optoelectron. 2018, 39, 65-76.

(C) 2018 by the authors. Licensee MDPI, Basel, Switzerland. This article is an open access article distributed under the terms and conditions of the Creative Commons Attribution (CC BY) license (http://creativecommons.org/licenses/by/4.0/). 